\title{
Comparative Study of CFRP-Confined CFST Stub Columns under Axial Compression
}

\author{
Ying Guo' ${ }^{1}$ and Yufen Zhang $\mathbb{D}^{2}$ \\ ${ }^{1}$ School of Civil Engineering, Tianjin University, Tianjin 300072, China \\ ${ }^{2}$ School of Civil and Transportation Engineering, Hebei University of Technology, Tianjin 300401, China \\ Correspondence should be addressed to Yufen Zhang; yufenzh@gmail.com
}

Received 25 May 2018; Revised 24 June 2018; Accepted 3 July 2018; Published 18 July 2018

Academic Editor: David M. Boyajian

Copyright ( $) 2018$ Ying Guo and Yufen Zhang. This is an open access article distributed under the Creative Commons Attribution License, which permits unrestricted use, distribution, and reproduction in any medium, provided the original work is properly cited.

\begin{abstract}
This paper presented a comparative study of concrete-filled steel tubular (CFST) stub columns with three different confinement types from carbon fiber reinforced polymer (CFRP): outer circular CFRP, inner circular CFRP, and outer square CFRP. The compressive mechanism and physical properties of the composite column were analyzed firstly aiming at investigating the confinement effect of CFRP. Ultimate axial bearing capacity of these three CFRP-confined CFST columns was calculated based on Unified Theory of CFST and elastoplastic limit equilibrium theory, respectively. Meanwhile, the corresponding tests are adopted to validate the feasibility of the two calculation models. Through data analysis, the study confirmed the ultimate strength calculation results of the limit equilibrium method were found to be more reliable and approximate to the test results than those of Unified Theory of CFST. Then axial bearing capacity of the pure CFST column was predicted to evaluate the bearing capacity enhancement ratio of the three types of composite columns. It was demonstrated that the averaged enhancement ratio is 16.4 percent, showing that CFRP-confined CFST columns had a broad engineering applicability. Through a comparative analysis, this study also confirmed that outer circular CFRP had the best confinement effect and outer square CFRP did better than inner circular CFRP. The confinement effect of CFRP increased with the decrease of concrete strength, and it was proportional with relative proportions of CFRP and steel under the same concrete strength.
\end{abstract}

\section{Introduction}

Carbon fiber reinforced polymers (CFRPs) have been widely used in repair and retrofit of deficient structures in recent decades, because externally bonded CFRP material in the form of sheets or plates is particularly well suited for flexure and shear $[1,2]$. In many engineering fields, the CFRP-metal composite tanks or tubes have been used widely, such as gas tank used in motor vehicle and pipeline system for transporting high pressure gas or liquid used in municipal engineering or chemical engineering. CFRP materials, as external jackets for the confinement of reinforced concrete columns, can enhance strength and ductility [3-6]. The superior mechanical and physical properties of CFRP make them excellent candidates to repair and retrofit steel structures as well. Concrete-filled steel tubular (CFST) structures have been studied and used in civil engineering widely for many years [7]. However, steel tubes are susceptible to degradation due to corrosion and its thin-walled section before concrete hardening [8], which results in the decrease of axial strength of the CFST column [9]. Therefore, the CFRP-metal tube can also be used in civil engineering, for example, the CFRP-steel composite tube infilled with concrete has been used as the column [10], and CFRP has also been used to reinforce damaged CFST column [11]. As discussed by Gu [12], Li et al. [13], and Wang et al. [14], most of the research conducted has focused on the use CFRP for CFST structure. Carbon fiber sheets or plates are attached to a steel tube or concrete in a CFST member to increase its bearing capacity and ductility. It was concluded that the ultimate lateral strength and flexural stiffness of CFRP-repaired CFST beam-columns increased with the 
increasing number of CFRP layers. Meanwhile, the ductility of specimens increased slightly with the number of CFRP layers. And, as discussed by Tao et al. [15], the CFRP cylinder can also impede buckling of the stub column leading to dramatic improvements in buckling and postbuckling behavior of the entire system. Wang et al. $[16,17]$ conducted axial compression experiments for thirty-two circular CFRPconfined CFST columns and twenty-four square CFRPconfined CFST columns. Analyses of the tested results show that the steel tube and its outer CFRP material can cooperate both longitudinally and transversely. Therefore, all these studies draw upon the concepts that complementary action between steel tube and concrete was strengthened through the higher confinement of CFRP.

Upon the abovementioned research, other types of composite columns have also been proposed. Karimi et al. [18] proposed a type of FRP-encased steel-concrete composite columns in which a circular FRP was placed around the steel I-section and had the concrete filled between the steel I-section and the FRP tube. Feng et al. [19] proposed a steel-concrete-FRP-concrete column which had a square steel tube as the outer layer and a circular filament-wound FRP tube as the inner layer, with concrete filled both between these two layers and within the FRP tube. The results of these studies showed that the strength of concrete, FRP, and steel could be effectively utilized in the composite columns.

All those research achievements confirmed that the composite column has its feasibility in theoretical research and engineering practice, showing a great potential for more development. Compressive strength is an important parameter for structural members, and most of those researches listed above were concentrated on the superposition method to calculate the ultimate compressive strength, so different formulas were deduced for every cross section of the CFRPconfined CFST columns. Therefore, the purpose of this paper is to build unified methods applicative to different sections of the composite column by the idea of Unified Theory of CFST and limit equilibrium theory. The focus of this study is to investigate three different technology CFRPs to strengthen CFST stub columns through a comparative study of three different confinement types: outer circular CFRP, inner circular CFRP, and outer square CFRP. Compressive mechanism and physical properties of these three CFRP-confined CFST columns were analyzed firstly aiming at investigating the confinement effect of CFRP on CFST columns. Two theoretical calculation models are presented to obtain the axial compressive capacity of CFRP-confined CFST columns. One is the Unified Theory of CFST [20]: the equivalent confinement coefficient is proposed with consideration of different sections of steel tubes and CFRP cylinders, and then formulas are derived from Unified Theory of CFST to predict the bearing capacity of the composite column under compression. The other is elastoplastic limit equilibrium method: twin-shear unified strength theory (TDUST) [21] is applied to analyze the ultimate state of steel tube and concrete, respectively, and then the ultimate bearing capacities of the composite column are obtained by the limit equilibrium method. The theoretical predictions were compared with the experimental results to validate the feasibility of the two calculation models. Lastly, the CFRP confinement effects on the axial bearing capacity were analyzed by comparison of these three CFRP-confined CFST columns.

\section{Working Mechanism}

Based on the summary of existing researches, three types of CFRP-confined CFST columns are considered with different CFRP confinements including outer circular CFRP, inner circular CFRP, and outer square CFRP, as shown in Figure 1. The CFRP cylinder is wrapped outside the circular CFST column in Type a; CFRP cylinder is placed inside the square CFST in Type b, and CFRP cylinder is wrapped outside the square CFST column in Type c. As can be seen in Figure 1, steel tubes together with the confined concrete can resist the axial compression remarkably, while the CFRP cylinders can provide the lateral confinement to the steel tube or concrete directly and make the composite column behave better indirectly.

As we all know, during the process of compression of the composite columns, there exists horizontal deformation when the vertical load acts on the whole section. Take the example of Type a in Figure 1, concrete is filled in the circular tube wrapped by the CFRP sheet, so its simplified model of stress can be plotted in Figure 2.

Concrete's horizontal deformation coefficient was small at the beginning of the axial load, so the lateral stress $p$ from steel tubes and CFRP sheet is not evident. With the increasing axial compression, concrete's horizontal deformation starts to gradually increase especially after the column yielding. There would be many microcracks happened in concrete after the column entered into plastic stage [22], but both the CFRP cylinder and steel tube can confine the concrete to postpone its expansion. The concrete can be regarded as three-dimensioned compressed, the steel tubes can be regarded as thin-walled cylinders, and CFRP is only tensile in the circumferential direction as shown in Figure 2. The ultimate state considers the following failure modes of the CFRP-confined CFST column: steel tube bucking and CFRP sheet rupturing [23, 24]. Although the CFRP cylinder has no direct contribution to the axial bearing capacity, the transverse fiber sheets contribute to the strength enhancement by confining the CFST column in whole (see Type a, $\mathrm{c}$ in Figure 1) or in part (see Type b in Figure 1), leading to a higher compressive strength of the column. Therefore, the wrapping CFRP can lead to a significant improvement in the inelastic axial deformation capacity prior to buckling and an improved load carrying capacity after buckling.

\section{Calculations by Unified Theory of CFST}

Unified Theory of CFST was presented by Professor Zhong Shan-tong in 1993 [25]. It considered CFST as a unified body, and a new composite material was used to study its behaviors. It was a new method to design and simplify the design work. Unified Theory of CFST has been extended to calculate the compressive strength of the composite CFST 


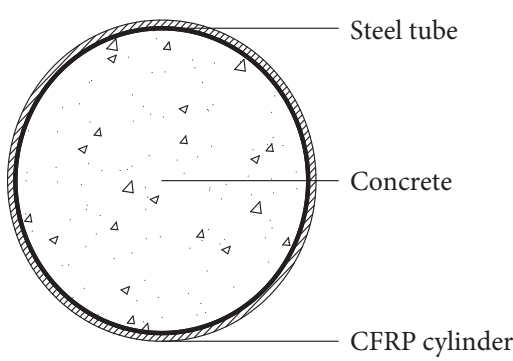

(a)

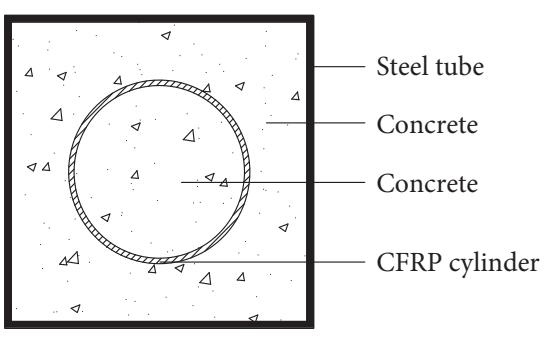

(b)

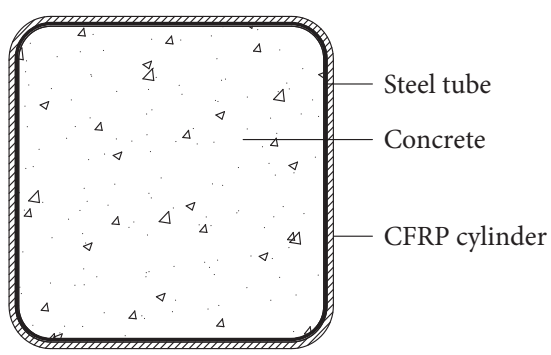

(c)

FIgURE 1: Cross section types of CFRP-confined CFST columns. (a) Outer circular CFRP. (b) Inner circular CFRP. (c) Outer square CFRP.

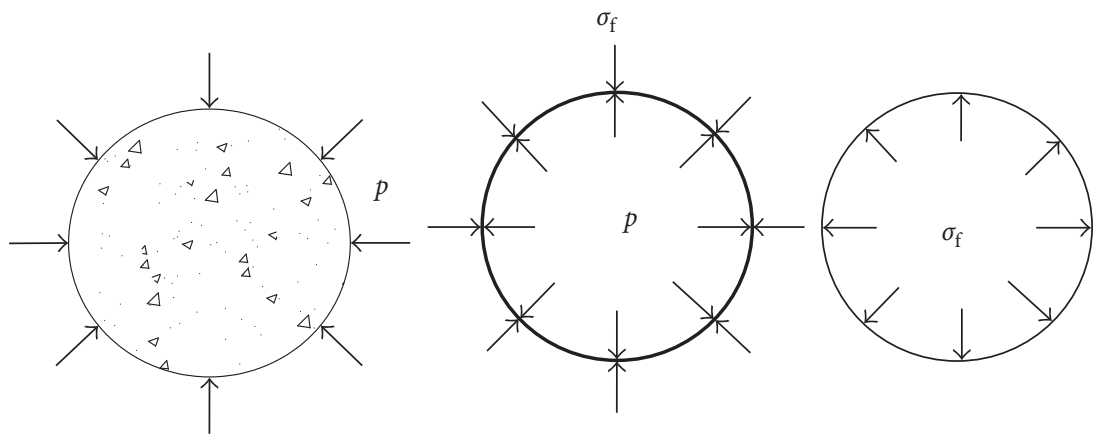

Figure 2: Stress model in the composite column under compression. (a) Concrete. (b) Steel tube. (c) CFRP cylinder.

columns with various confining materials and various cross sections under various loadings [26]. For CFRP-confined CFST columns, the concrete is still confined by the steel tube directly, and this confining effect is absolutely strengthened by the CFRP cylinder. One composite material can also be considered to assess its behaviors, but the confining effect should be reevaluated deriving from the steel tube and CFRP cylinder. We can extend deeper research works into CFRPconfined CFST columns, so one equivalent confinement coefficient $\xi_{\text {ssc }}$ is presented, which can be expressed as

$$
\xi_{\mathrm{ssc}}=\frac{k_{\mathrm{s}} A_{\mathrm{s}} f_{\mathrm{s}}+k_{\mathrm{cf}} A_{\mathrm{cf}} f_{\mathrm{cf}}}{A_{\mathrm{c}} f_{\mathrm{ck}}},
$$

where $A_{\mathrm{s}}, A_{\mathrm{c}}$, and $A_{\mathrm{cf}}$ are the cross section areas of the steel tube, concrete, and CFRP cylinder, respectively; $f_{\mathrm{s}}$ and $f_{\mathrm{cf}}$ are the yield strengths of steel and CFRP, respectively; $f_{\mathrm{ck}}$ is the standard compressive strength of the concrete; $k_{\mathrm{s}}$ and $k_{\mathrm{cf}}$ are the coefficients with consideration of section form of the confining material. Because in the composite column, there are two difform materials to confine concrete, the effect of restraint is different from circular section to square section. Generally, the coefficient of circular section is taken as the basic parameter 1 , and for square section, it is 0.74 [27].

Then the composite strength $f_{\text {ssc }}$ of the stub column can be calculated by the formula derived from Unified Theory of CFST, and the equation can be expressed as

$$
f_{\mathrm{ssc}}=\left(1.212+a \xi_{\mathrm{ssc}}+b \xi_{\mathrm{ssc}}^{2}\right) f_{\mathrm{ck}},
$$

where $a$ and $b$ reflect the contributions of confining materials and concrete, respectively. They can be calculated by the following formula:

$$
\begin{aligned}
& a=\frac{0.1759 f_{\mathrm{ss}}}{235+0.974}, \\
& b=\frac{-0.1038 f_{\mathrm{ck}}}{20+0.0309},
\end{aligned}
$$

where $f_{\text {ss }}$ is the weighted average of the confining materials including both the steel tube and CFRP cylinder, which is calculated by

$$
f_{\mathrm{ss}}=\frac{A_{\mathrm{s}} f_{\mathrm{s}}+A_{\mathrm{cf}} f_{\mathrm{cf}}}{A_{\mathrm{s}}+A_{\mathrm{cf}}} .
$$

Therefore, it is recommended to use the following formula to calculate the bearing capacity of the CFRP-confined CFST stub column.

$$
N_{\mathrm{y}}^{1}=A f_{\text {ssck }}
$$

where $A$ is the cross section area of the whole column and $N_{\mathrm{y}}^{1}$ is the bearing capacity calculated by Unified Theory of CFST.

\section{Calculations by Limit Equilibrium Theory}

4.1. Basic Assumptions. In this theoretical model for obtaining the axial compressive capacity, we can quantitatively analyze how much the confinement is influenced by the steel tube and CFRP. The interface between the steel tube and the CFRP sheet is constrained; the radial stress in the steel tube is ignored, and the steel tube is under biaxial stress; the CFRP material is linear elastic, and only the lateral stress is considered, so the stress along the fiber direction is 
considered; the radial stress and the longitudinal stress are ignored.

Based on the above assumptions, the ultimate axial bearing capacity of CFRP-confined CFST columns can be calculated by

$$
N_{\mathrm{y}}^{2}=N_{\mathrm{s}}+N_{\mathrm{c}}
$$

where $N, N_{s}$, and $N_{c}$ are vertical bearing capacities of the steel tube and concrete, respectively. $N_{y}^{2}$ is the bearing capacity calculated by limit equilibrium theory. In the state of limit equilibrium, every part of the composite column can be analyzed using TSUST [21].

4.2. Twin-Shear Unified Strength Theory (TSUST). The TSUST considers the two larger principal shear stresses and the corresponding normal stresses and their different effects on the failure of materials. When the relationship function between them reaches one ultimate value, the material can be defined as failure at this state which is formulated as follows:

$$
\begin{array}{ll} 
& F=\tau_{13}+b \tau_{12}+\beta\left(\sigma_{13}+b \sigma_{12}\right)=C, \\
\text { when } \quad & \tau_{12}+\beta \sigma_{12} \geq \tau_{23}+\beta \sigma_{23}, \\
& F^{\prime}=\tau_{13}+b \tau_{23}+\beta\left(\sigma_{13}+b \sigma_{23}\right)=C, \\
\text { when } \quad \tau_{12}+\beta \sigma_{12} \leq \tau_{23}+\beta \sigma_{23},
\end{array}
$$

where $\tau_{12}, \tau_{23}$, and $\tau_{13}$ are the principal shear stresses, $\tau_{13}=\left(\sigma_{1}-\sigma_{3}\right) / 2, \tau_{12}=\left(\sigma_{1}-\sigma_{2}\right) / 2$, and $\tau_{23}=\left(\sigma_{2}-\sigma_{3}\right) / 2$; $\sigma_{12}, \sigma_{23}$ and, $\sigma_{13}$ are the corresponding normal stresses on the principal shear stress element; $\sigma_{1}, \sigma_{2}$, and $\sigma_{3}$ are the principal stresses, $\sigma_{1} \geq \sigma_{2} \geq \sigma_{3}$; $b$ is a weighting coefficient, reflecting the relative effect of the intermediate principal shear stress $\tau_{12}$ or $\tau_{23}$ on the strength of materials; $C$ equals to the material strength; $\beta$ is the influence coefficient of positive stress on material damage. Denoting the tension-compression strength ratio as $\alpha=\sigma_{t} / \sigma_{c}$, we rewrite (7a) and (7b) in terms of principal stresses as follows:

$$
\begin{gathered}
F=\sigma_{1}-\frac{\alpha}{1+b}\left(b \sigma_{2}+\sigma_{3}\right)=\sigma_{\mathrm{t}}, \quad \text { when } \sigma_{2} \leq \frac{\sigma_{1}+\alpha \sigma_{3}}{1+\alpha}, \\
F^{\prime}=\frac{1}{1+b}\left(\sigma_{1}+b \sigma_{2}\right)-\alpha \sigma_{3}=\sigma_{\mathrm{t}}, \quad \text { when } \sigma_{2} \geq \frac{\sigma_{1}+\alpha \sigma_{3}}{1+\alpha} .
\end{gathered}
$$

4.3. Formula of Ultimate Capacity. By the principle of same area, the square cross section of the steel tube can be transformed into a circular one. $B$ and $t_{\mathrm{s}}$ are the side length and thickness of the square steel tube, and $r_{\mathrm{o}}$ and $t_{\mathrm{o}}$ are the radius and thickness of the equivalent circular steel tube, respectively. The formulas are shown as follows:

$$
\begin{aligned}
& r_{\mathrm{o}}=\frac{B}{\sqrt{\pi}}=0.5642 B, \\
& t_{\mathrm{o}}=\frac{r_{\mathrm{o}}-\left(B-2 t_{\mathrm{s}}\right)}{\sqrt{\pi}}=r_{\mathrm{o}}-0.5642\left(B-2 t_{\mathrm{s}}\right) .
\end{aligned}
$$

Meanwhile, because the confinement of the square steel is uneven along its side, the equivalent reduction factor should be considered to reduce the same confinement of the equivalent circular steel tube. Denoting thickness-side length ratio $v=t / B$, the expression of the equivalent reduction factor $\xi=66.4741 v^{2}+0.9919 v+0.41618 \quad$ [28]. Meanwhile, there are effective and noneffective confining zones of the concrete inside the square steel tube. In this paper, the concrete strength reduction factor is considered to ignore these two influences. The concrete strength reduction factor is taken as $\gamma_{\mu}=1.67 D_{\mathrm{o}}^{-0.112}$ [28], where $D_{\mathrm{o}}$ is the inside diameter of the equivalent circular steel tube.

The simplified stress model of confined concrete is shown in Figure 2(a). The stresses can be explicated by $0>\sigma_{1}=\sigma_{2}>\sigma_{3}, \sigma_{1}=\sigma_{2}=p$. For $\sigma_{2} \geq\left(\left(\sigma_{1}+\alpha \sigma_{3}\right) /(1+\alpha)\right)$. Substituting them into the stress expression of TSUST, the following expression can be obtained as

$$
\sigma_{3}=\sigma_{\mathrm{c}}=f_{\mathrm{ck}}+k_{\mathrm{c}} p,
$$

where $k_{\mathrm{c}}$ is the lateral stress coefficient. In TSUST, $k_{\mathrm{c}}$ can be calculated by cohesion and friction angle at material failure state. According to the test of Richart [22], $k_{\mathrm{c}}$ has been taken as 4.1 simply here; $p$ is the lateral stress on the concrete, and the lateral stress on concrete is from both the steel tube and CFRP cylinder for Type a and $c$ as shown in Figure 1, so it can be expressed by

$$
p=\sigma_{\mathrm{f}}+\sigma_{\mathrm{rs}}
$$

where $\sigma f=t_{\mathrm{cf}} f_{\mathrm{cf}} / r_{\mathrm{cf}}$ and $\sigma_{\mathrm{rs}}=t_{\mathrm{s}} f_{\mathrm{s}} / r_{\mathrm{s}} ; t_{\mathrm{cf}}$ and $r_{\mathrm{cf}}$ are the thickness and radius of the CFRP cylinder, respectively; $t_{\mathrm{s}}$ and $r_{\mathrm{s}}$ are the thickness and radius of the steel tube, respectively. While for Type b in Figure 1, the concrete should be divided into exterior concrete and internal concrete under different lateral stresses. Exterior concrete is only confined by the steel tube, but internal concrete is considered both the steel tube and CFRP cylinder. Then the axial bearing capacity of the concrete can be expressed as

$$
N_{\mathrm{c}}=\left(f_{\mathrm{ck}}+k_{\mathrm{c}} p\right) A_{\mathrm{c}} \text {. }
$$

As can be seen in Figure 2(b), the steel tube is constrained by inside concrete so it can bear some vertical load under the ultimate state of the whole column, $\eta$ is assumed as the strength reduction factor of the steel tube, and then the stress state of steel tubes can be explicated by $\sigma_{3}=\sigma_{\mathrm{z}}=\eta f_{\mathrm{s}}, \sigma_{2}=\sigma_{r}=0, \sigma_{1}=\sigma_{\theta}=p r_{\mathrm{o}} / t_{\mathrm{s}}$. For $\left|\sigma_{3}\right|>\sigma_{1}$ and $\sigma_{2} \geq\left(\left(\sigma_{1}+\sigma_{3}\right) /(1+\alpha)\right)$, substitute them into the stress expression of TSUST, the following expression can be obtained:

$$
\frac{p r_{\mathrm{o}}}{t_{\mathrm{s}}(1+b)}-\eta f_{\mathrm{s}}=f_{\mathrm{s}}
$$




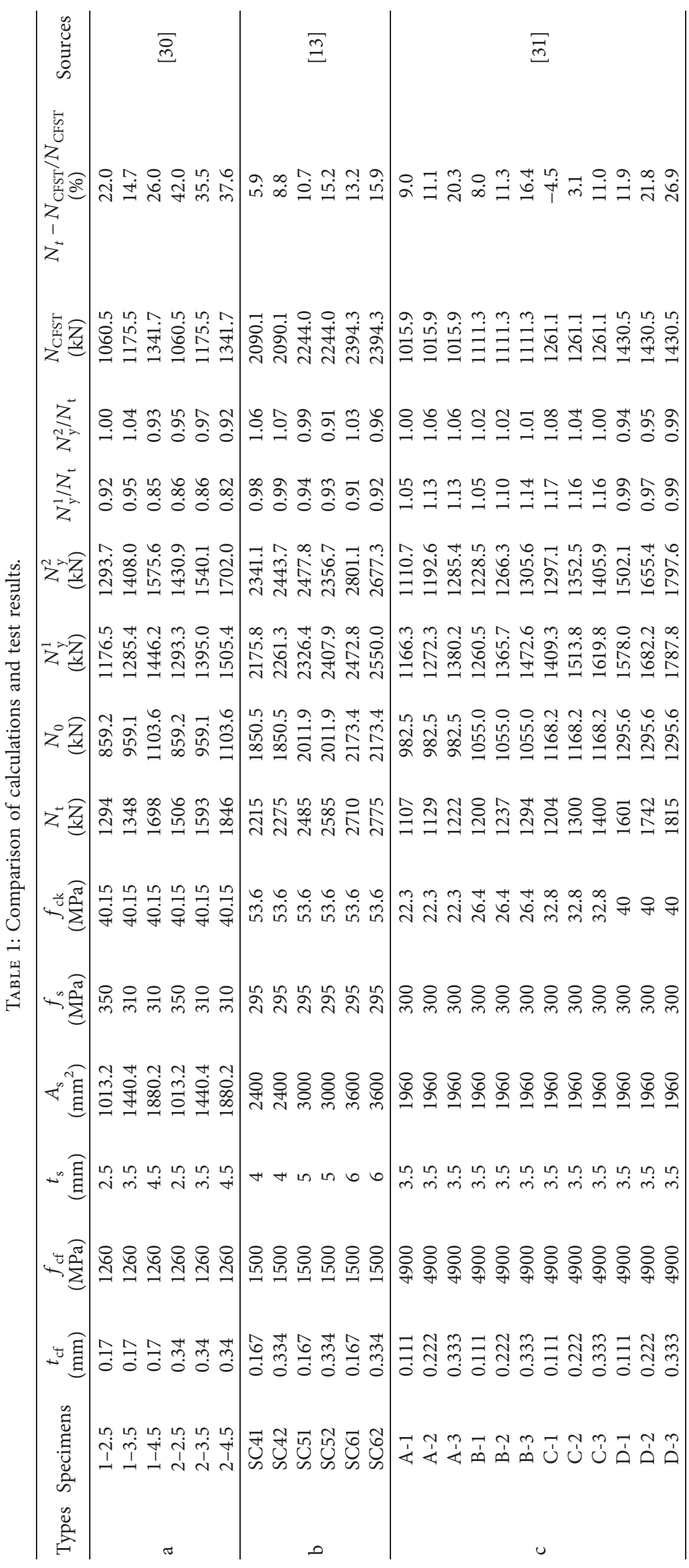




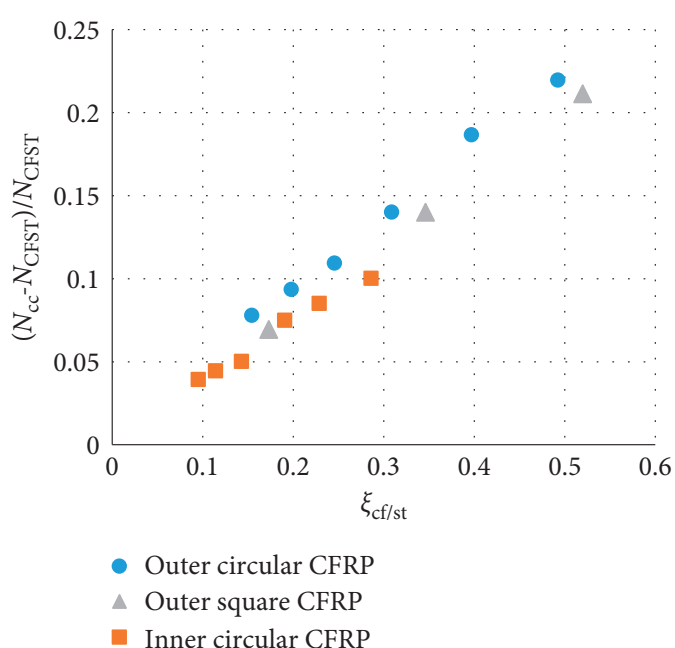

(a)

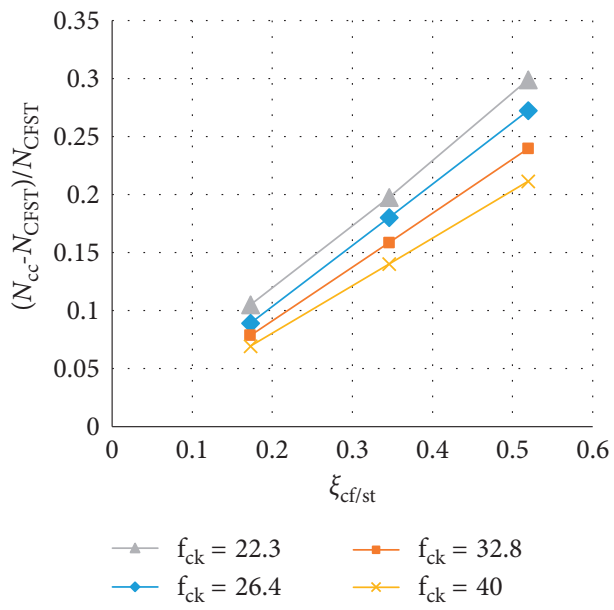

(b)

FIgURE 3: Relationship between $\left(N_{\mathrm{cc}}-N_{\mathrm{CFST}}\right) / N_{\mathrm{CFST}}$ and $\xi_{\mathrm{c} / \mathrm{st}}$. (a) $f_{\mathrm{ck}}=40.15$. (b) Different $f_{\mathrm{ck}}$.

Then $\eta$ was obtained as 0.65 by experimentation and statistical data [29], so the ultimate capacity of the steel tube can be calculated by

$$
N_{\mathrm{s}}=n f_{\mathrm{s}} A_{\mathrm{s}} .
$$

Lastly, the ultimate capacity of CFRP-confined CFST column can be expressed as follows:

$$
N_{\mathrm{y}}^{2}=\eta f_{\mathrm{s}} A_{\mathrm{s}}+\left(f_{\mathrm{ck}}+k_{\mathrm{c}} p\right) A_{\mathrm{c}} .
$$

\section{Comparison and Analysis}

The three types of CFRP-confined CFST stub columns shown in Figure 1 have been tested under axial compression $[13,30,31]$. Calculations $N_{\mathrm{y}}^{1}$ and $N_{\mathrm{y}}^{2}$, obtained by Unified Theory of CFST and limit equilibrium theory, respectively, are listed in Table 1 together with the test results $N_{\mathrm{t}}$. The calculated results both have good agreement with the test results within small errors less than $20 \%$. Comparing the value of $N_{\mathrm{y}}^{2} / N_{\mathrm{t}}$ and $N_{\mathrm{y}}^{1} / N_{\mathrm{t}}$ shown in Table 1 , we can find that $N_{\mathrm{y}}^{2}$ obtained by the limit equilibrium method is more accurate and reliable than $N_{\mathrm{y}}^{1}$ obtained by the method of Unified Theory of CFST. On the other hand, the method of Unified Theory of CFST is simple and easy to realize since it just considers the column as one composite material, while the method of limit equilibrium method sound complicated since it applies TSUST to analyze every component of the composite column. Therefore, these two methods can both be applied to investigate the axial bearing capacity of CFRPconfined CFST stub columns, and they can provide reference for engineering design. Then axial bearing capacity of pure CFST columns can be predicted by the limit equilibrium method in order to evaluate the bearing capacity improvement due to the CFRP confinement. By reviewing test results, the bearing capacity enhancement rate is described as the expression of $\left(N_{\mathrm{t}}-N_{\mathrm{CFST}}\right) / N_{\mathrm{CFST}}$ as shown in Table 1. It was found that the averaged bearing capacity enhancement rate of CFRP-confined CFST stub columns is 16.4 percent in comparison with the pure CFST columns. Because the CFRP sheet is very thin, it is demonstrated that the bearing capacity of the composite columns improves more than the corresponding pure CFST columns with the nearly same cross section area. Therefore, it is very applicable to use CFRP to strengthen the CFST column, and the composite columns can result in significant savings in column size, which ultimately realize the material potency and bring economic benefits.

Through data analysis of the calculated and experimental results, it can be found that concrete strength and the relative proportions of CFRP and steel are the main parameters to influence the axial bearing capacity of the composite column. The confining mechanism of CFRP and axial bearing capacity improvement needs to be validated, so the relative proportions of CFRP and steel is proposed according to the concept of equivalent confinement coefficient $\xi_{\text {ssc }}(1)$. The relative proportions of CFRP and steel $\xi_{\mathrm{cf} / \mathrm{st}}$ considers strength, content, and confining effect of section form, that is,

$$
\xi_{\mathrm{cf} / \mathrm{st}}=\frac{k_{\mathrm{cf}} A_{\mathrm{cf}} f_{\mathrm{cf}}}{k_{\mathrm{s}} A_{\mathrm{s}} f_{\mathrm{s}}} .
$$

Since the test results of the bearing capacity of the stub columns have a certain degree of dispersion and some parameters need to be taken as the same value, the calculated axial bearing capacity $N_{\mathrm{cc}}$ is used to describe the bearing capacity enhancement ratio with the expression of $\left(\mathrm{Ncc}_{\mathrm{cc}^{-}}\right.$ $\left.N_{\text {CFST }}\right) / N_{\text {CFST }}$, which reflects the function of the CFRP cylinder to confine the CFST column, where $N_{\text {CFST }}$ is the calculated value for the corresponding pure CFST column. $N_{\mathrm{cc}}$ is obtained by limit equilibrium theory.

The relationship between $\left(N_{\mathrm{cc}}-N_{\mathrm{CFST}}\right) / N_{\mathrm{CFST}}$ and $\xi_{\mathrm{cf} / \mathrm{st}}$ for the three types of composite columns is shown in Figure 3. In reference to the experimental data in Table 1, $f_{\mathrm{ck}}$ of Type $\mathrm{b}$ and Type $\mathrm{c}$ is taken as $40.15 \mathrm{MPa}$ similar to Type a, and Figure 3(a) shows the relationship between 
$\left(N_{\mathrm{cc}}-N_{\mathrm{CFST}}\right) / N_{\mathrm{CFST}}$ and $\xi_{\mathrm{cf} / \mathrm{st}}$ under the same concrete strength. The relationship is linear and directly proportional to the CFRP-wrapped composite columns with the outer circular CFRP or outer square CFRP because the outer CFRP cylinder strengthens the whole CFST column. But for the inner circular CFRP-confined columns, there is no linear proportion because inner CFRP only strengthens its inside concrete directly. It can also be found that outer circular CFRP has the best confinement effect to provide the highest bearing capacity enhancement ratio at the same relative proportions of CFRP and steel. Meanwhile, outer square CFRP does better than inner circular CFRP as shown in Figure 3(a), that is, CFRP as external jackets can provide the better confinement than the internal one. On the other hand, we choose the basic parameters of outer square CFRP-confined CFST columns in Table 1 to get the relationship between $\left(N_{\mathrm{cc}}-N_{\mathrm{CFST}}\right) / N_{\mathrm{CFST}}$ and $\xi_{\mathrm{cf} / \mathrm{st}}$ under different concrete strength as shown in Figure 3(b). For every group, the steel tube and the concrete are the same, so the bearing capacity enhancement ratio is linear and direct proportional to the content of the CFRP cylinder. Among the four groups, with the decrease of concrete strength, the bearing capacity enhancement ratio increases with the improvement of relative proportions of CFRP and steel. It indicates that the confinement effect of CFRP increases with the decrease of concrete strength. The reason is mainly that the contributions of the CFRP cylinder are the displacement resistance of the CFST column, and low-strength concrete has the better deformation capacity to make the CFRP play better especially during the postbuckling process.

\section{Conclusions}

This paper presented a comparative study of concrete-filled steel tubular (CFST) stub columns with three different confinement types from carbon fiber reinforced polymer (CFRP): outer circular CFRP, inner circular CFRP, and outer square CFRP. CFRP-confined CFST column takes the advantage of not only the good performance of CFST but also a substantial improvement in higher confinement of CFRP. The compressive mechanism and physical properties of the composite column were analyzed firstly aiming at investigating the confinement effects of the different CFRP on CFST Columns.

Two methods based on Unified Theory of CFST and elastoplastic limit equilibrium method have been applied to investigate the axial bearing capacity of CFRP-confined CFST stub columns. The calculated results have good agreement with the test results. Through data analysis, the study confirmed the ultimate strength calculation results of limit equilibrium method were found to be more accurate and reliable than that of Unified Theory of CFST. Then axial bearing capacity of pure CFST columns was predicted to evaluate the bearing capacity improvement factor coming from the CFRP confinement. It was demonstrated that the averaged enhancement ratio is 16.4 percent, showing that the three kinds of CFRP-confined CFST columns had a broad applicability.
CFRP can increase CFST members' bearing capacities significantly because complementary action between the steel tube and concrete is strengthened through CFRP. The relationship between the bearing capacity enhancement ratio and relative proportions of CFRP and steel is nearly linear, especially for the CFRP-wrapped columns with the outer circular CFRP or outer square CFRP. Through a comparative analysis, this study confirmed that outer circular CFRP had the best confinement effect and outer square CFRP did better than inner circular CFRP. The confinement effect of CFRP increased with the decrease of concrete strength, and it was proportional with relative proportions of CFRP and CFST under the same concrete strength.

\section{Data Availability}

All data used for this paper are publicly available and accessible online. We have annotated the entire data building process and empirical techniques presented in the paper. We have given formal citations in article references. While we did not directly draw upon these sources for the empirical analysis, these efforts confirmed our understanding of the scope, scale, and accuracy of the CFRP-confined CFST columns.

\section{Conflicts of Interest}

The authors declare that they have no conflicts of interest.

\section{Acknowledgments}

The authors would like to acknowledge the support provided by the Chinese National Science Foundation (Grant no. 51478004). Meanwhile, the financial support from Hebei University of Technology is also appreciated.

\section{References}

[1] O. Chaalal and M. Shahawy, "Performance of fiber-reinforced polymer: wrapped reinforced concrete column under combined axial flexural loading," ACI Structure Journal, vol. 97, no. 4, pp. 659-668, 2000.

[2] Y. Xiao, "Applications of FRP composites in concrete columns," Advances in Structural Engineering, vol. 7, no. 4, pp. 335-343, 2004.

[3] J. G. Teng, Y. L. Huang, L. Lam, and L. P. Ye, "Theoretical model for fiber reinforced polymer-confined concrete," Journal of Composites for Construction, vol. 11, no. 2, pp. 201-210, 2007.

[4] J. G. Teng, T. Jiang, L. Lam, and Y. Z. Luo, "Refinement of a design-oriented stress-strain model for FRP-confined concrete," Journal of Composites for Construction, vol. 13, no. 4, pp. 269-278, 2009.

[5] Y. Zheng, L. F. Zhang, and L. P. Xia, "Investigation of the behaviour of flexible and ductile ECC link slab reinforced with FRP," Construction and Building Materials, vol. 166, pp. 694-711, 2018.

[6] Y. Zheng and L. P. Xia, "Investigation of the ultimate capacity of NSM FRP-strengthened concrete bridge deck slabs," Arabian Journal of Science and Engineering, vol. 43, pp. 1597-1615, 2018. 
[7] Z. F. Amir and H. R. Sami, "Confinement model for axially loaded concrete confined by circular FRP tubes," ACI Structure Journal, vol. 98, no. 4, pp. 451-461, 2001.

[8] L. H. Han, Concrete-Filled Steel Tube Structures-Theory and Design, Science Press, Beijing, China, 2nd edition, 2007.

[9] B. C. Chen and T. L. Wang, "Overview of concrete filled steel tube arch bridges in China," Practice Periodical on Structural Design and Construction, vol. 14, no. 2, pp. 70-80, 2009.

[10] Y. Che, Q. L. Wang, and Y. B. Shao, "Compressive performances of the concrete filled circular CFRP-steel tube (CCFRP-CFST)," International Journal of Advanced Steel Construction, vol. 8, no. 4, pp. 311-338, 2012.

[11] Z. Tao, L. H. Han, and L. L. Wang, "Compressive and flexural behaviour of CFRP repaired concrete-filled steel tubes after exposure to fire," Journal of Constructional Steel Research, vol. 63, no. 8, pp. 1116-1126, 2007.

[12] W. Gu, "Study on mechanics of concrete-filled CFRP-steel tube column," Thesis for doctor degree, DaLian Maritime University, Dalian, China, 2007.

[13] G. C. Li, L. Ma, and J. L. Yang, "Bearing capacity of short columns of high-strength concrete filled square steel tubular with inner CFRP circular tubular under axially compressive load," Journal of Shenyang Jianzhu University, vol. 24, no. 1, pp. 62-66, 2008.

[14] Q. L. Wang, G. Y. Wang, and F. Han, "Experimental study on concentrically compressed stub columns reinforced by concrete filled CFRP-steel tube," in 4th International Conference on Advances in Steel Structures, Elsevier Science Ltd., pp. 671-676, London, UK, 2005.

[15] Z. Tao, L. H. Han, and J. P. Zhuang, "Using CFRP to strengthen concrete-filled steel tubular columns: stub column tests," in 4th International Conference on Advances in Steel Structures, Elsevier Science Ltd., pp. 701-706, London, UK, 2005.

[16] Q. L. Wang, S. E. Qu, Y. B. Shao, and L. M. Feng, "Static behavior of axially compressed circular concrete filled cfrpsteel tubular (c-cf-cfrp-st) columns with moderate slenderness ratio," Advanced Steel Construction, vol. 12, no. 3, pp. 263-295, 2016.

[17] Q. L. Wang, Z. Zhao, Y. B. Shao, and Q. L. Li, "Static behavior of axially compressed square concrete filled CFRP-steel tubular (S-CF-CFRP-ST) columns with moderate slenderness," Thin-Walled Structures, vol. 110, pp. 106-122, 2017.

[18] K. Karimi, M. J. Tait, and W. W. EI-Dakhakhni, "Testing and modeling of a novel FRP-encased steel-concrete composite column," Composite Structures, vol. 93, no. 5, pp. 1463-1473, 2011.

[19] P. Feng, S. Cheng, Y. Bai et al., "Mechanical behavior of concrete-filled square steel tube with FRP-confined concrete core subjected to axial compression," Composite Structures, vol. 123 , no. 5 , pp. 312-324, 2015.

[20] S. T. Zhong, Unified Theory of Concrete Filled Steel Tubular Structure, Tsinghua University Press, Beijing, China, 2006.

[21] M. H. Yu, Unified Strength Theory and Its Applications, Springer Press, Berlin, Heidelberg, Germany, 2004.

[22] F. E. Richart, A. Brandtzaeg, and R. L. Brown, "A study of the failure of concrete under combined compressive stresses," Bulletin No. 185, Engineering Experimental Station, University of Illinois, Urbana, IL, USA, 1928.

[23] Q. L. Wang, W. Gu, and Y. H. Zhao, "Experimental study on concentrically compressed concrete filled circular CFRP-steel composite tubular stub columns," China Civil Engineering Journal, vol. 38, no. 10, pp. 44-48, 2005.

[24] A. H. Varma, R. Sause, and J. M. Ricles, "Development and validation of fiber model for high strength square concrete filled steel tube beam-column," ACI Structural Journal, vol. 102, no. 1, pp. 73-84, 2005.

[25] S. T. Zhong, "New concept and development of research on concrete-filled steel tube (CFST)," in Proceeding of 2nd International Symposium on Civil Infrastructure Systems, pp. 9-12, Hong Kong, December 1996.

[26] Y. F. Zhang and Z. Q. Zhang, "Study on equivalent confinement coefficient of composite CFST column based on unified theory," Mechanics of Advanced Materials and Structures, vol. 23, no. 1, pp. 22-27, 2016.

[27] H. T. Chen, "Theoretical study on continuity of basic behavior of every-sectioned CFT stub columns under axial loads," Thesis for doctor degree, Harbin Institute of Technology, Harbin, China, 2001.

[28] X. W. Li and J. H. Zhao, "Mechanics behavior of axial loaded short columns with concrete-filled square steel tube," Chinese Journal of Highway and Transport, vol. 19, no. 4, pp. 77-81, 2006.

[29] Y. F. Zhang, J. H. Zhao, and W. F. Yuan, "Study on compressive bearing capacity of concrete filled square steel tube column reinforced by circular steel tube inside," Journal of Civil Engineering and Management, vol. 19, no. 6, pp. 787795, 2013.

[30] W. Gu and H. N. Li, "Research in the properties of the concrete filled steel tube columns with CFRP composite materials," Advanced Materials Research, vol. 163-167, pp. 3555-3559, 2011.

[31] Q. L. Wang and Y. B. Shao, "Compressive performances of concrete filled square CFRP-steel tubes (S-CFRP-CFST)," Steel and Composite Structures, vol. 16, no. 5, pp. 455-480, 2014. 


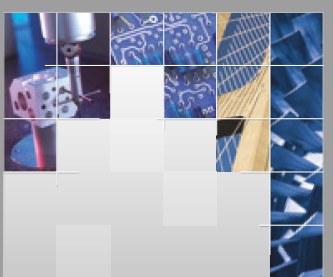

\section{Enfincering}
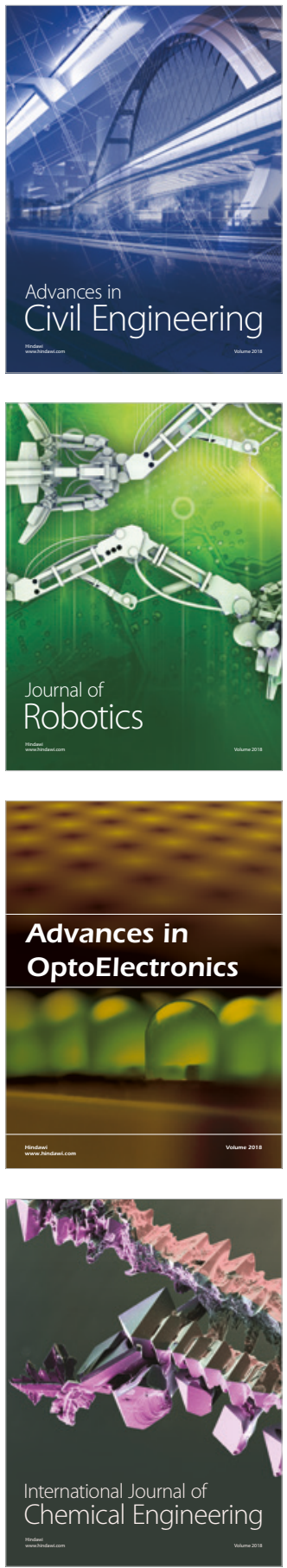

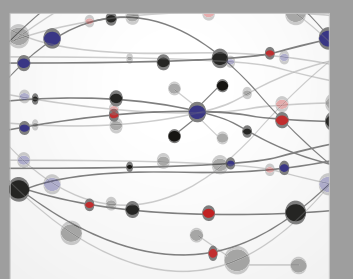

\section{Rotating \\ Machinery}

The Scientific World Journal

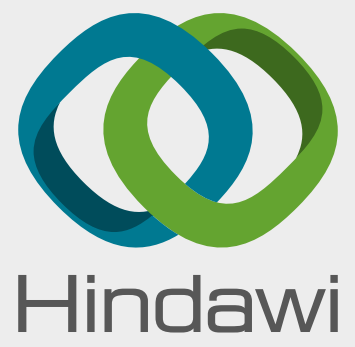

Submit your manuscripts at

www.hindawi.com
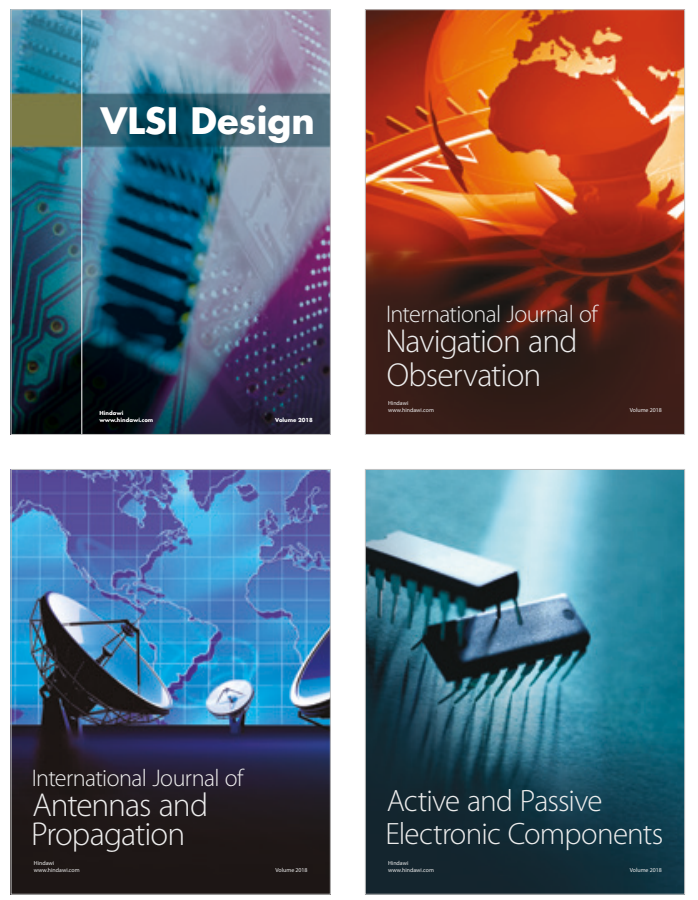
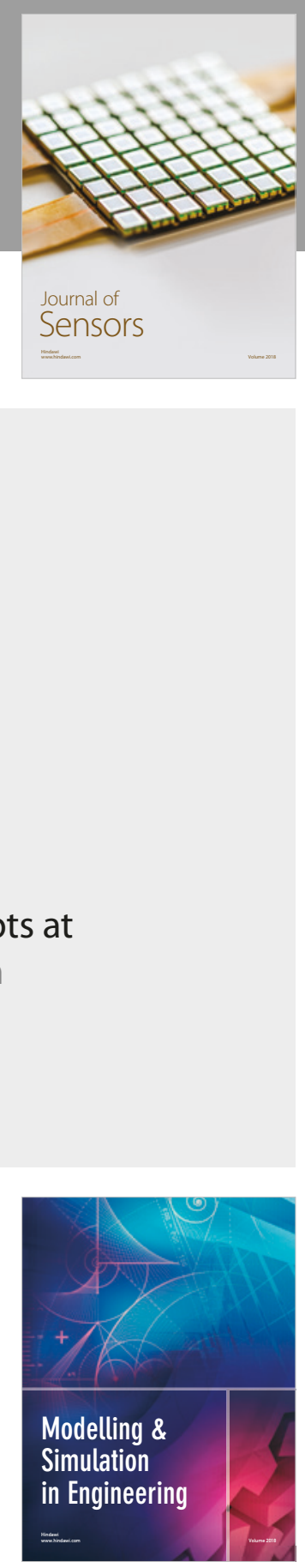

\section{Advances \\ Multimedia}
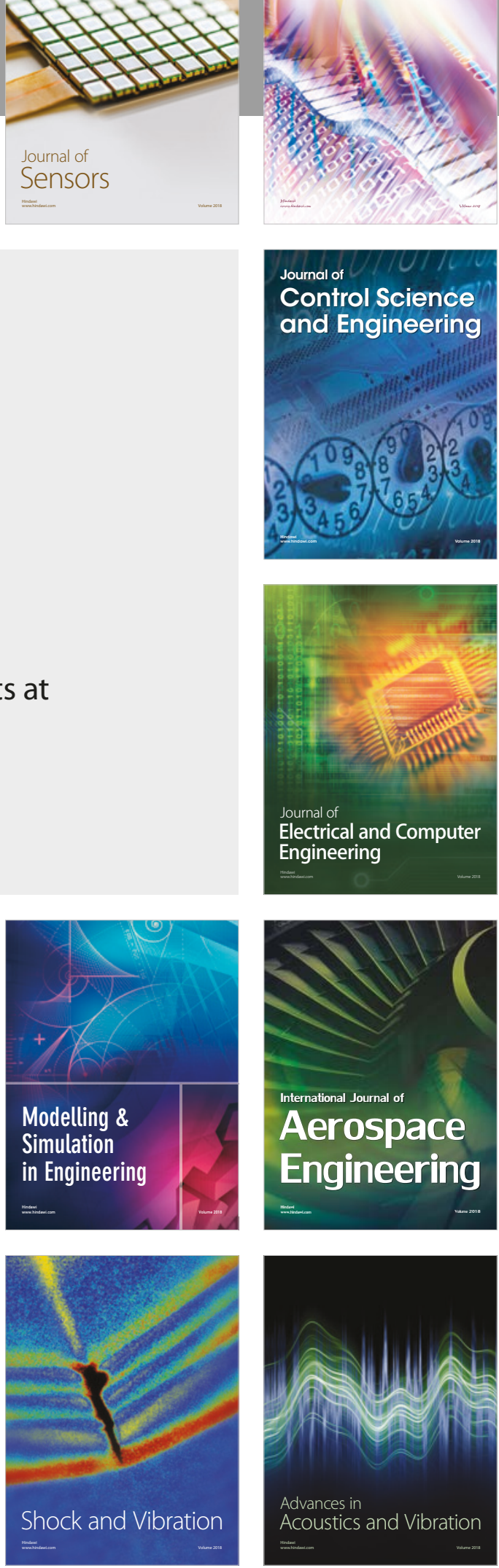